Políticas públicas: nova abordagem 


\title{
Políticas públicas: pontos de método e experiências ${ }^{1}$
}

\author{
ANA LYDIA SAWAYA
}

A UNIDADE entre as várias experiências culturais que compõem a sociedade se dá quando a todas é oferecida a possibilidade de se desenvolverem. A democracia é a convivência de uma pluralidade de respostas que os homens admitem sobre as exigências e perguntas fundamentais da pessoa e da sociedade. A vida democrática é um encontro das várias respostas aos problemas, exigências e problemática que a dura realidade coloca.

O Estado pode agir facilitando e dando espaço às várias respostas que nascem da criatividade e liberdade da pessoa no seu agir individual e comunitário, tornando-se assim, no seu dinamismo, leigo e democrático, ou pode ignorar as tentativas de resposta efetivas já dadas, mesmo que em estado embrionário, e basear a convivência somente nas exigências que correspondam a um critério que ele, como detentor do poder, define. Essas duas possibilidades são determinantes na execução, mas antes ainda e mais importante, no pensar e definir as políticas públicas que coordenarão a intervenção para solucionar os problemas públicos vigentes num determinado país.

Este artigo relata resumidamente duas experiências, uma relativa a uma organização não-governamental $(\mathrm{ONG})$ de dimensão internacional e com fortes raízes no Brasil e outra relativa a uma Secretaria de Estado, nas suas tentativas e respostas efetivas para a realização de políticas públicas no Brasil centradas na pessoa, entendendo essa como protagonista e sujeito do seu próprio desenvolvimento.

\section{Cinco pontos}

\section{Centralidade da pessoa}

De acordo com a doutrina social católica, o homem é uno na realidade do seu eu. Portanto, qualquer política pública que procure respeitar o ser humano na sua liberdade e dignidade de escolha sobre a própria vida, que tem também, como interesse, o bem comum de uma sociedade livre e democrática, deve procurar intervir considerando o "homem integral, o homem todo inteiro, em toda a verdade da sua objetividade espiritual e corporal", não se podendo sobrepor a isso “divisões ou oposições pré-concebidas" (João Paulo II, discurso à Unesco, 2.6.1980).

O que determina, ou seja, o que dá forma a essa unidade da pessoa, do en? É aquele elemento dinâmico que, por meio das perguntas últimas, das exigências fundamentais com que se exprime, guia a expressão pessoal e social da pessoa. É 
nessa dimensão que se encontra o significado último da vida de cada pessoa, a raiz da suas escolhas e da busca da felicidade pessoal, e em que se encontram seus anseios mais fundamentais, que podem ser chamados de "senso religioso" (Giussani, 2001).

$\mathrm{O}$ senso religioso mostra-se, pois, a raiz da qual brotam os valores. $\mathrm{O}$ valor, em última instância, consiste na perspectiva da relação entre algo contingente e a totalidade, o absoluto. A responsabilidade da pessoa, mediante todos os tipos de solicitações que lhe vêm do impacto com o real, compromete-se com a resposta às perguntas que o senso religioso exprime (ibidem). É nesse nível que se encontram perguntas como: Para que serve a minha vida? O que, no fundo, eu desejo e espero da vida? Nesse sentido, uma política pública que quer criar uma cultura de responsabilidade e não apenas deseje agir "sobre" as estruturas carentes, podendo inevitavelmente cair numa certa violência para com o outro, deve manter vivo aquele desejo original da pessoa do qual brotam desejos e valores: a relação com o infinito (o significado último da vida), que torna a pessoa sujeito verdadeiro e ativo da história.

Uma cultura de responsabilidade só pode partir do senso religioso. Esse ponto de partida impele os homens também a se unirem na sociedade, segundo uma totalidade e uma liberdade impossíveis numa política pública realizada de forma mais ou menos impositiva ou relativamente assistencialista, na qual não há um sujeito livre em busca do significado da própria vida, mas apenas o objeto da intervenção.

Assim, uma política pública que tenha a centralidade da pessoa em toda a sua integralidade como ponto de partida fundamental visará compartilhar com a pessoa atendida as suas necessidades e o sentido da vida. Isso requer o encontro e o diálogo com as pessoas atendidas e o conhecimento detalhado da sua condição de vida, valores e cultura. Esse compartilhar implica ainda um comover-se pelo seu destino pessoal.

\section{Partiv do positivo}

Se é necessário partir, antes de tudo, não da análise e do projeto de quem detém o poder para a realização de políticas públicas, mas do conhecimento das reais necessidades e do sentido da vida de quem será atendido, buscando a responsabilidade autêntica e pessoal deste, é preciso também conhecer o que já existe de recursos positivos naquela pessoa ou na realidade. Antes de partir do que falta ou da vulnerabilidade da comunidade a ser atendida, precisa-se conhecer o que já existe de positivo, ou seja, conhecer quais as estratégias de sobrevivência que as pessoas atendidas têm realizado com relativa eficiência. Pois cada pessoa, cada comunidade, ainda que pobre, representa uma riqueza.

Isso significa que a política pública deve procurar valorizar e fortalecer aquilo que as pessoas têm construído, isto é, aquele tecido social e o conjunto de experiências que constituem o seu patrimônio de vida. "É portanto, no compromisso com esse primado da socialidade livre e criativa diante do poder que se 
demonstram a força e a duração da responsabilidade pessoal" (ibidem). Esses fatores influenciam diretamente o sucesso em longo prazo da política pública e a efetividade da intervenção.

\section{Fazer com}

Um projeto "caído do céu" é violento porque não é participado (não conta com a participação de quem deve ser o sujeito da ação e não mero objeto); ou é ineficaz na medida em que fica restrito somente ao assistencial.

A doutrina social católica lembra que a pessoa humana é definida pelo "desejo".

O desejo é como uma fagulha com a qual se acende o motor. Todos os movimentos humanos nascem desse fenômeno, desse dinamismo constitutivo do homem. O desejo acende o motor do homem; e então ele se põe a buscar pão e água, o trabalho, a mulher ou o homem; põe-se a buscar a poltrona mais cômoda ou a casa mais decente, interessa-se por saber por que alguns têm tanto e outros não tem nada, interessa-se por saber por que alguns são tratados de um certo modo e ele não - tudo isso justamente por força do engrandecimento, da dilatação, do amadurecimento, desses estímulos que ele possui dentro de si. (ibidem)

Por isso, a realização de políticas públicas que não partam do compartilhar desejos comuns, "fazendo com" e não apenas "para" a pessoa atendida, ajudando-a a reconhecer e tornar mais fácil a realização do seu desejo, tenderá a ser ineficaz: "Não existe real movimento ou mudança da pessoa sem que uma afeição tenha sido despertada" (ibidem).

\section{Desenvolvimento de corpos intermediários e subsidiaridade}

A sociedade nasce da livre agregação das pessoas e das famílias. Realizar um projeto de desenvolvimento significa favorecer as possibilidades de agregação, reconhecer e valorizar a constituição de corpos sociais intermediários, como também de um tecido social rico de participação e de co-responsabilidade.

É no primado da sociedade diante do Estado que se preserva a cultura de responsabilidade. Primado da sociedade, portanto: como tecido criado por relações dinâmicas entre movimentos sociais que criando obras e agregações, constituem comunidades intermediárias, e assim exprimem a liberdade das pessoas potencializada pela forma associativa. Um partido que sufoca, que não favorece ou que não defende essa rica criatividade social, contribui para criar ou manter um Estado prepotente sobre a sociedade. Tal Estado reduz-se a ser funcional apenas para os programas de quem está no poder, e a responsabilidade é evocada simplesmente para suscitar consenso para as coisas já programadas. (ibidem)

Nesse mesmo sentido, o princípio de subsidiaridade da Doutrina Social Católica afirma que "o poder deve intervir nos lugares em que a pessoa falha, em que a pessoa não consegue construir o que quer e a que tem direito por corresponder à sua natureza, e não nos lugares em que a pessoa não consegue fazer o que o chefe do governo imagina". Assim, 
um homem tem um desejo e busca satisfazê-lo. Outros homens, sentindo o mesmo desejo, buscam satisfazê-lo e compreendem que se reunindo, satisfazem cada um o próprio desejo de modo mais fácil e muito melhor. Quanto mais se dá liberdade à criação das comunidades intermediárias e quanto mais o poder subsidia essa ação, mais feliz será a humanidade. (ibidem)

\section{Parceria}

Nos projetos de desenvolvimento, é fundamental estabelecer uma real parceria entre as entidades públicas e privadas envolvidas, colocando em ação grandes quantidades de recursos, favorecendo sinergias. O princípio de subsidiaridade e a facilitação para a criação e fortalecimento de corpos intermediários colocam o Estado na posição de serviço à pessoa e à sociedade. Se esses dois princípios regem as políticas públicas centradas na pessoa, então, necessariamente, esse Estado buscará parcerias não apenas para garantir ou aumentar a quantidade de recursos, mas como garantia do bem comum e da democracia.

\section{Primeiro exemplo: programas de desenvolvimento urbano}

O desenvolvimento humano de um povo não deriva primeiramente nem do dinheiro, nem das ajudas materiais, nem das estruturas técnicas, mas do amadurecimento da mentalidade e dos costumes.

É o homem o protagonista do desenvolvimento, não o dinheiro ou a técnica. (João Paulo II, 1990)

Com essa frase o professor Enrico Novara, coordenador da Fundação “Associação Voluntários para o Serviço Internacional" (AVSI), organização não-governamental sem fins lucrativos, criada em 1972 e hoje empenhada em cerca de cem projetos de cooperação ao desenvolvimento, em 35 países do mundo (América Latina, África, Leste Europeu e Oriente Médio), define a missão de sua fundação. A Fundação AVSI visa apoiar o desenvolvimento humano nos países em desenvolvimento em sintonia com os ensinamentos da Doutrina Social Católica, com particular atenção à educação e à promoção da dignidade da pessoa humana em todas as suas expressões. A AVSI está credenciada desde 1996 junto ao Conselho Econômico e Social das Nações Unidas em Nova York (Ecosoc), tem status consultivo junto à ONU para o Desenvolvimento da Indústria, em Viena (Unido), e está inserida na Special List das organizações não-governamentais da Organização Internacional da ONU para o Trabalho em Genebra (OIT). Atua nas áreas de educação, infância e família, na integração das áreas urbanas informais, na prevenção e cuidados com a saúde, na formação profissional e encaminhamento ao trabalho. Possui projetos de intervenção em agricultura, ambientais e de segurança alimentar, além de ajuda humanitária de emergência, entre outros projetos.

Nos principais projetos desenvolvidos no Brasil, a AVSI atua em convênio com o poder público. As vantagens desse tipo de parceria são, principalmente, a possibilidade de manter uma clara identidade, sendo um organismo da sociedade civil focalizado no sucesso de uma determinada ação no tempo, ao mesmo tempo que permite uma ação social que não depende exclusivamente do poder 
público e da burocracia inerente ao processo. Ter uma identidade clara permite ainda o pluralismo, o diálogo e a parceria a partir de interesses comuns, pois o perigo da ideologia é quando essa não se explicita como tal, mas pretende ser a única reposta a um problema social. Ser um organismo da sociedade civil que atua em programas de utilidade pública em convênio com o Estado tem também a vantagem de fortalecer a sociedade organizada, tornando-a propositiva de ações sociais de interesse próprio; e não apenas reduzindo as ações da sociedade a ações reivindicativas. Essas iniciativas geram uma sociedade mais construtiva.

Um outro fator interessante da Fundação AVSI é que seus sócios principais são outras entidades sem fins lucrativos, inclusive 23 ONG locais que estão presentes nos vários países onde atua. A AVSI como estrutura é, portanto, uma rede de associações. Esse é o motivo para a AVSI pertencer ao Conselho Econômico e Social da ONU, uma vez que representa uma rede de desenvolvimento. Um exemplo desse modo de atuação da AVSI é no combate à Aids em Uganda, onde a AVSI participa do projeto em nível nacional. Depois de anos de atuação, os resultados mostraram que Uganda é hoje um dos poucos países africanos em que a curva de crescimento da doença reverteu, diminuindo a incidência da doença no país.

Um outro lugar de atuação histórica da AVSI é o Brasil. Na Bahia, junto com a Companhia de Desenvolvimento Urbano do Estado da Bahia (Conder), a AVSI coordena o Projeto de Apoio Técnico e Social do Programa Ribeira Azul, que envolve projetos de urbanização de Novos Alagados e outras áreas precárias com trinta mil famílias atendidas e sessenta milhões de dólares de orçamento (AVSI, 2002). Para esse programa, a AVSI foi destinatária do maior financiamento do Banco Mundial para uma ONG. A metodologia aplicada ao projeto pela AVSI visa seguir os princípios da doutrina social católica descritos anteriormente e procura favorecer, sobretudo, o desenvolvimento da pessoa como tal. O fo-co fundamental é a pessoa como motor de um processo de desenvolvimento. Sem estimular a liberdade da pessoa não é possível nenhum desenvolvimento duradouro. Essa afirmação tem implicações objetivas na forma de gerir os projetos.

Todo o desenvolvimento do projeto parte da avaliação e conhecimento detalhados da comunidade. Um dos principais problemas que temos no Brasil para a construção de políticas públicas eficientes é a falta de conhecimento, de como conhecer a realidade. Que não significa como analisar a realidade, ou como subdividir a realidade para conhecê-la melhor. No Brasil, aliás, são muito avançadas as análises desse tipo, em relação a outros países. Mas trata-se de como conhecêla na sua totalidade. Portanto, se a pessoa é o ponto de partida para conhecer a realidade em que ela está inserida, esse conhecimento pressupõe compartilhar aquela realidade, o que significa compartilhar com a população atendida os anseios, os desejos, as necessidades que vivem, e o que já conseguiram construir como estratégias de sobrevivência (Solymos, 2002; Novara et al., 2003). Sem isso, é impossível encontrar a pessoa. O gerador de políticas públicas deve então participar do que está acontecendo naquela realidade. 


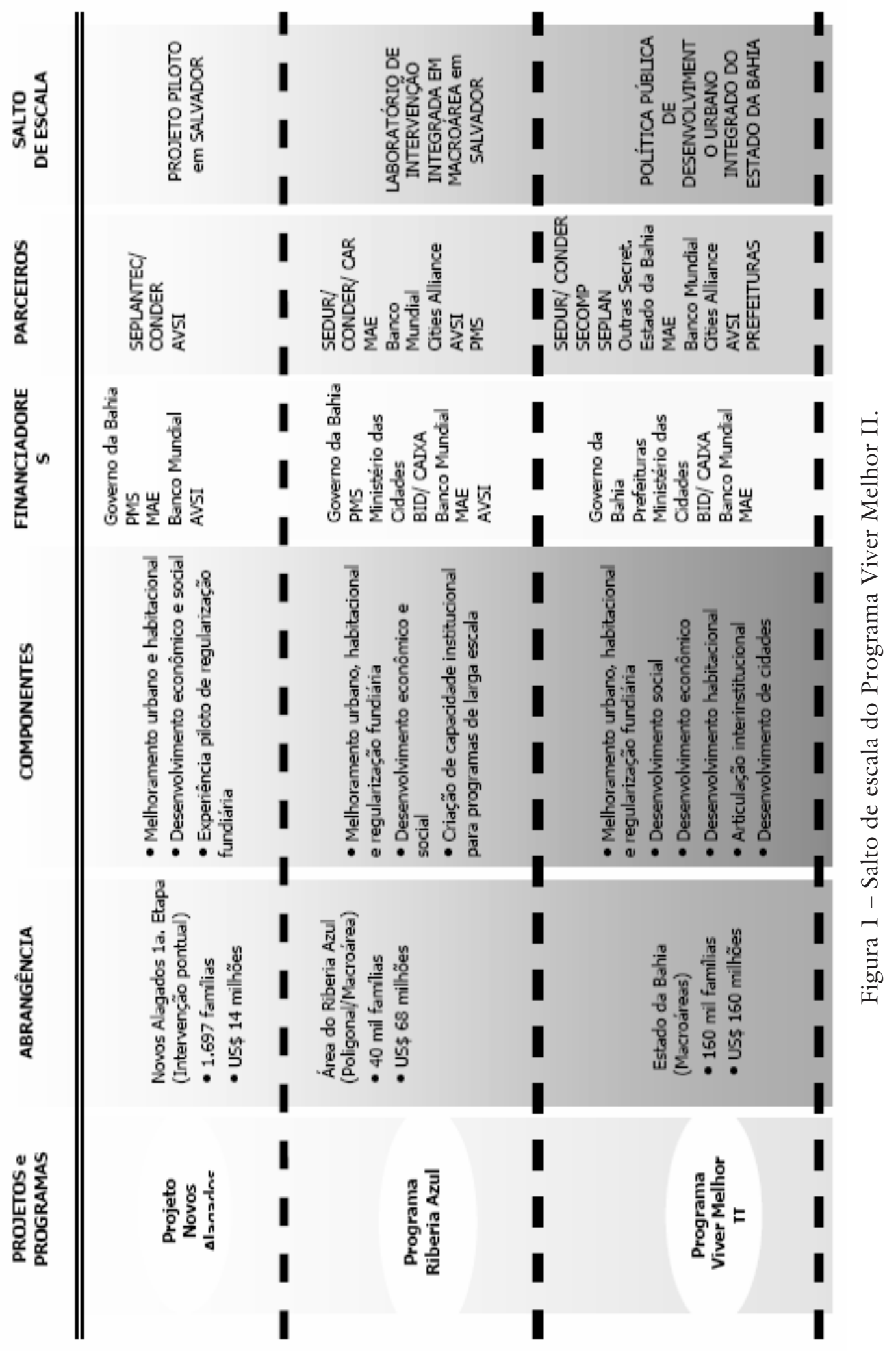


O projeto envolve quatro fases:

1. Avaliação e conhecimento da comunidade.

2. Planejamento da infra-estrutura urbana.

3. Planejamento da intervenção social e ambiental.

4. Ações.

Essa abordagem é mais ampla do que aquela que muitas vezes rege as políticas públicas no Brasil baseadas na distribuição de renda ou na ampliação do acesso aos serviços, pois considera e identifica os recursos já existentes na comunidade. As primeiras iniciativas de atuação são então no sentido de mapear esses recursos para, em seguida, reforçá-los e subsidiá-los através de cursos de formação e educação, e reforço dos corpos intermediários. Esse tipo de intervenção parte do oferecimento de recursos para microcrédito, cooperativas e microempresas; busca o reforço dos atores presentes na comunidade, melhoria das moradias ou construção de novas; além de projetos de saneamento e ambientais, entre outros.

No campo da educação e formação, uma iniciativa importante é o reforço escolar para melhoria da qualidade da educação. Essa iniciativa tem um grande impacto na ação pública de promoção do desenvolvimento e combate à pobreza, especialmente aquela estrutural. Nesse sentido, o acesso é muito mais do que garantir um direito genérico de dinheiro e serviços.

Um exemplo da necessidade do conhecimento das estratégias de sobrevivência para o combate à pobreza é a necessidade de se conhecer a real condição de vida da família e dos serviços de educação, saúde e de promoção humana, nos projetos de reurbanização de favelas. Muitas vezes esses projetos se resumem a uma preocupação urbanística, de construção de estruturas e oferecimento de serviços, mas sem ter a preocupação estratégica de procurar conhecer os recursos reais de proteção das famílias, como as fontes de renda e os tipos de atividades profissionais, os limites orçamentários para gastos com transporte, a distância dos locais de trabalho etc. Por isso, um aspecto fundamental do método utilizado pela AVSI nos projetos de urbanização de favelas em Salvador e Belo Horizonte é mapear os domicílios de acordo com suas redes de atuação profissional (tipo de profissão e recursos utilizados para o trabalho e geração de renda), condições de saúde (dependência de unidades hospitalares ou de saúde), unidades escolares utilizadas pelos filhos, laços familiares e de parentesco etc.

Esse mapeamento é utilizado para o desenho e planejamento do novo agrupamento urbano. A desconsideração desses fatores e a pouca participação da população no processo de urbanização e construção das moradias levam a um "nãopertencimento" da população atendida ao novo local e sua alta mobilidade e "venda". Uma intervenção que vem de "fora" daquela comunidade pode facilmente destruir o "patrimônio" que permite as famílias do local sobreviverem, o que pode provocar o abandono da nova moradia (Novara, 2003). A AVSI, utilizando esse método de conhecimento da realidade global da pessoa atendida, tem observado em Salvador um índice de venda dos domicílios após cinco anos de urbanização de apenas $4 \%$. 
Dados de projetos de remanejamento de famílias do Banco Mundial revelam valores significativamente mais altos $(25 \%-30 \%)$. As famílias, nesse caso, privilegiaram a casa à soma de dez ou quinze mil reais, o que representa uma soma significativamente alta para essas famílias. Se levarmos em conta que a população atendida vive em palafitas há várias gerações e, portanto, está “acostumada” àquela condição de vida, essa mudança se tornou grande e estável.

Um outro dado interessante tem sido o grande número de projetos e organizações criadas e realizadas pela população que dobrou na segunda fase do projeto, mostrando uma evolução crescente de organização da comunidade atendida.

Esses achados mostraram que o projeto tem gerado um conjunto de bens e de serviços dentro da comunidade que é muito mais do que a presença do esgoto e da própria casa, tornando-se um lugar de "moradia" estável. Para realizar esse trabalho, foi mantido um escritório de campo durante cinco anos que permitiu a realização das quatro fases do projeto; sempre com a preocupação de associar o desenvolvimento urbano ao desenvolvimento social.

O plano de desenvolvimento social tem como fatores: a educação, a família, o trabalho e o apoio aos corpos intermediários, compreendendo que são esses os reais atores do desenvolvimento.

O projeto de urbanização de Novos Alagados em Salvador prevê a retirada das palafitas que foram construídas ao longo de anos sobre o mar, aterramento e a reconstrução de casas com toda a infra-estrutura urbana adequada. Essa infraestrutura comporta a criação de projetos educativos e o reforço dos corpos intermediários como o Centro de Apoio a Família, creches, reforço escolar, Centro de Saúde, Centro de Qualificação Profissional etc. Criou-se também uma cooperativa de eletricistas e outra de pedreiros que foram responsáveis pela construção de muitas das casas. A população recebe uma casa-embrião com a possibilidade de ampliá-la por meio das cooperativas. De todos os recursos do projeto, 25\% são destinados ao apoio desses corpos intermediários.

Essa consideração sobre a necessidade de um conhecimento global da pessoa atendida leva a uma outra consideração: de que as intervenções devem ser territoriais. Não se pode pensar um programa igual para todo o Brasil que não leve em conta que as realidades territoriais são diferentes. O conhecimento global da pessoa implica o conjunto de recursos já agregados, em associações e corpos intermediários e todos os atores que podem participar do processo, desde o Estado, a iniciativa privada, as universidades. É claro que as diretrizes devem ser comuns, mas é necessário construir parcerias locais que sejam reais.

Assim, uma outra forma de entender a pobreza compreende que a pessoa em situação de pobreza não encontrou condições de colocar em movimento todos os talentos que ele efetivamente tem. Dessa forma, o reforço a esses talentos torna-se estratégia prioritária. Só como critério de comparação, o HabitarBID, que é a política adotada pelo Ministério das Cidades, aplica cerca de $4 \% \mathrm{em}$ desenvolvimento social, apenas. 

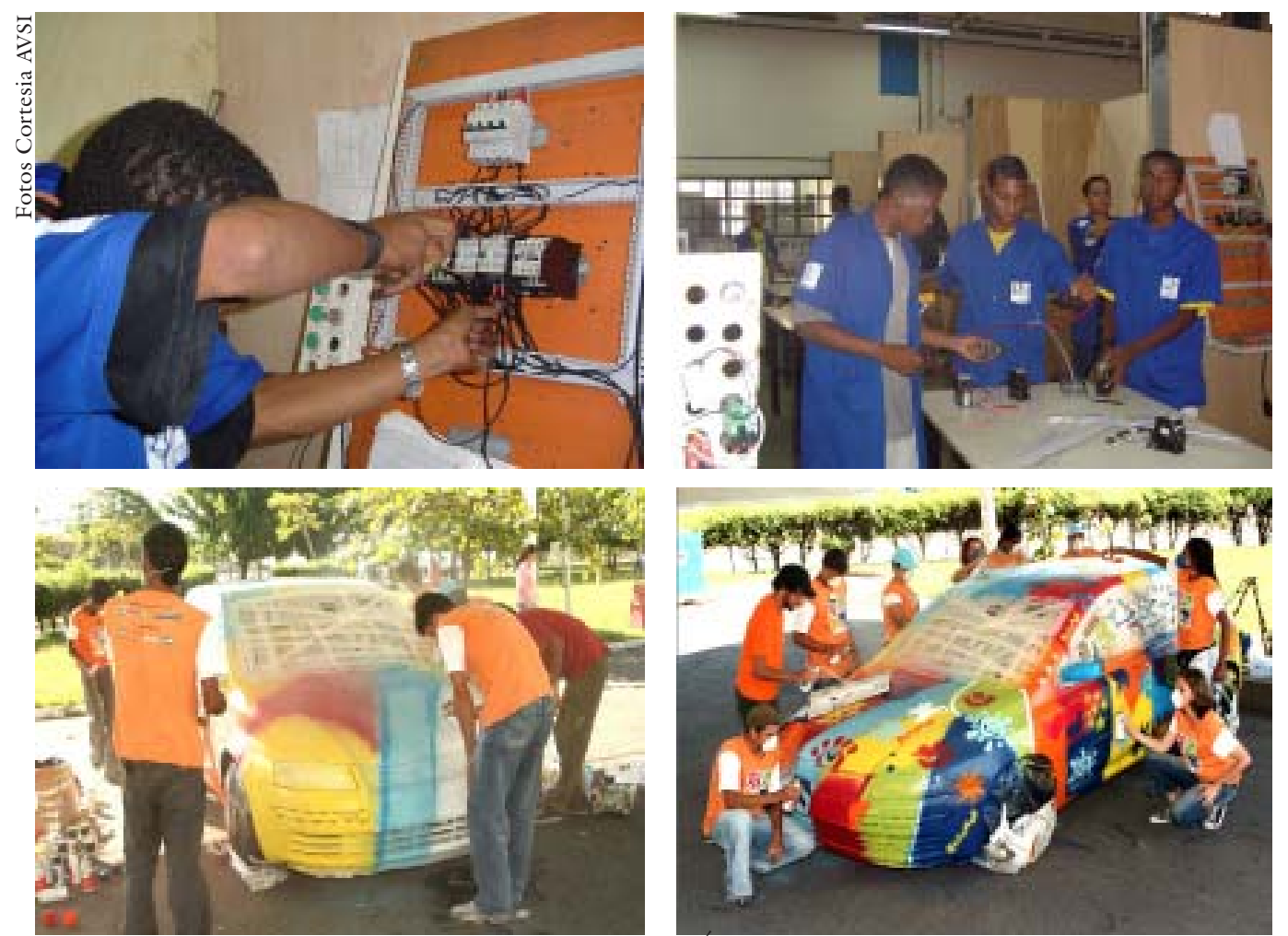

Cooperativa de eletricistas e jovens do Projeto Arvore da Vida, em parceria com a Fiat.

Exemplos da aplicação dos cinco princípios de método descritos anteriormente podem ser encontrados em todos os projetos desenvolvidos pela AVSI no Brasil. A AVSI coopera ainda com uma rede de quarenta instituições privadas que atendem sete mil crianças, com quinhentos funcionários, em Manaus, Macapá, Recife, Salvador, Brasília, Belo Horizonte, São Paulo e Rio de Janeiro. As atividades desenvolvidas são: Centros de Acolhida para crianças em situação de risco físico e social, atendimento a crianças desnutridas, escolas infantis, reforço escolar para crianças e adolescentes de sete a dezesseis anos que freqüentam escolas públicas, e centros de apoio à família (Cogo \& Capitanio, 2004). A AVSI desenvolve cursos para educadores do ensino infantil e de formação para todos os funcionários. Todas essas atividades visam à melhoria da qualidade do atendimento, mediante formação, acompanhamento e aumento da disponibilidade de recursos. Aqui também a estratégia é o fortalecimento sistemático de corpos intermediários, por meio de convênios com universidades e centros de referência no Brasil e exterior, com a realização de vídeo e teleconferências, e com o suporte financeiro de um projeto de apoio a distância. No mundo, esse projeto de apoio a distância conta com uma rede de 25 mil famílias, em sua grande maioria européias, que apóiam o atendimento de 24 mil crianças. No Brasil, essa rede apóia as quarenta instituições e não as famílias diretamente, para que seja possível garantir a continuidade para as iniciativas educativas e para garantir a presença e intervenção de um educador adulto capaz de avaliar a situação e as necessidades de cada criança e de sua família. 
Além disso, há também a perspectiva de ajudar as instituições apoiadas a se tornarem referência no bairro onde atuam. Esse suporte à entidade local tem permitido que ela se diversifique e possa servir como ponto de referência, como tem acontecido com várias das instituições brasileiras apoiadas. Uma creche ou escola infantil pode apoiar e promover então cursos de formação profissional para as famílias das crianças atendidas e até iniciativas de microcrédito, pois o melhor agente de microcrédito é o diretor da escola infantil, uma vez que tem relação estável com as famílias. E assim essas instituições são fortalecidas e podem se tornar também centro de referência no bairro. Esse percurso educativo baseado na formação e apoio das redes e instituições existentes nos locais atendidos é feito com cursos de extensão e convênios com universidades. É importante chamar a atenção de que essas iniciativas estão sendo realizadas em quarenta instituições em oito cidades brasileiras, o que pode ser um exemplo para uma política pública nacional.

Um último exemplo apresentado pelo professor Enrico Novara da AVSI foi sobre o projeto realizado em Betim, Minas Gerais, conjuntamente com a Fiat. Discutindo sua atividade de responsabilidade social, a Fiat buscou a AVSI para desenvolver um projeto de intervenção na comunidade local. A pergunta inicial foi: quais são os problemas daquela comunidade? Trata-se então da iniciativa privada que busca uma intervenção de utilidade pública. O projeto se iniciou com o mapeamento das instituições locais existentes, para conhecer o bairro que era muito violento. Identificou-se um pequeno grupo de seiscentos jovens que tinham problemas na escola. Daí partiu-se para iniciativas de reforço escolar e criação de iniciativas complementares à escola. Depois de um ano, 67\% desses melhoraram no sentido de diminuírem o fator vulnerabilidade na escola, definido por: freqüência, relacionamento, aprendizagem, participação/interesse, indisciplina.

Participaram do projeto 27 atores sociais, entre escolas, creches, associações, unidades de saúde, paróquias, conselho tutelar, polícia militar, rádios comunitárias, entre outros. A primeira parte do projeto foi então reduzir a vulnerabilidade das crianças por meio de atividades socioeducativas e acompanhamento da trajetória desses na escola junto com os professores. Um segundo passo representou um salto de escala, pela solicitação para que as instituições locais desenvolvessem projetos, tendo uma proposta clara e direcionada, uma vez que a Fiat se colocou com parceira e subsidiária, para assim ampliar a rede de parcerias. Os projetos visavam à geração de emprego e renda, e a função da AVSI foi a de estabelecer as demandas junto à Fiat para oferecer e orientar a população local para as atividades necessárias ao parceiro. Um exemplo dessa segunda parte do projeto foi a organização de uma rede de costureiras, na qual a AVSI entrou como intermediador.

\section{Segundo exemplo: programa de saude de Minas Gerais}

O segundo exemplo para um entendimento de políticas públicas tendo como base a centralidade da pessoa é um Programa de Gestão da Secretaria de 
Estado de Saúde de Minas Gerais. Esse exemplo não é de uma Organização da Sociedade Civil, mas da própria gestão do Estado. Fala o Dr. Marco Antônio Bragança de Matos a partir de uma análise pessoal do que, desde o início de 2003, ele tem acompanhado na Secretaria como membro da equipe de Gestão em Saúde, no Estado de Minas Gerais. Ele afirma ter observado uma grande mudança quanto à concepção de política pública nos últimos anos, existindo vários elementos dentro dos novos programas que, segundo o Dr. Marco Antônio, expressam a questão da centralidade da pessoa. Ele começa citando a Doutrina Social Católica: "A política, enquanto a forma de cultura mais completa, só pode ter como preocupação fundamental o homem" (Giussani, 2001). Colocar o homem no centro quando se trata de política pública pode parecer algo óbvio, uma vez que a política pública visa atender o homem ou o povo na sua necessidade.

Na experiência com planejamento em saúde pública, porém, o Dr. Marco Antônio vê a necessidade de retomar a cada momento, e diante de cada iniciativa, a preocupação de promover o homem como sujeito da própria mudança, de afirmar a liberdade do homem e a sua necessidade em toda a sua amplitude. Afirma, ainda, que é interessante entender que a política, como diz a citação de Giussani, é a forma mais completa de cultura. Pois a cultura é quem dá as rédeas, define a dinâmica, a forma de dar-se conta da realidade, de julgar a realidade e, conseqüentemente, é ela que determina a forma da atuação e do acompanhamento da realidade. É uma determinada cultura, aquela que permite intervenções a partir dessa interação contínua e dinâmica com a realidade (ou não, pois pode querer partir de preconceitos já determinados a priori); e isso de novo não é uma coisa óbvia.

$\mathrm{Na}$ saúde pública, é muito fácil se encaixar em determinados programas que existem há vários anos e seguir uma lógica já determinada, sem se preocupar com o conhecimento dinâmico que a realidade, sempre em mutação, impõe. Ao contrário, é necessária uma avaliação que pergunte sempre: estamos, como poder público, respondendo às necessidades de cada um dos dezoito milhões de mineiros? Essa é uma pergunta que sempre faço nas reuniões na Secretaria, disse o Dr. Marco Antônio, porque esse é o objetivo último de quem faz política pública. Essa não é uma questão utópica ou demagógica, mas é uma questão concreta, operativa, que exige um método adequado para responder à pessoa que encontramos e que espera nossa atenção e intervenção.

"A política verdadeira é a que defende uma novidade de vida no presente, capaz de modificar também a ordem do poder" (Giussani, 2001). "Uma novidade de vida no presente", isso é importante porque não é verdade que os gestores de política pública têm nas mãos a solução de todos os problemas, de maneira planejada e predefinida. Para uma concepção inteligente da política pública, é necessário buscar e encontrar a novidade que vem da própria realidade, que não vem de uma concepção a priori daquilo que somos capazes de pensar ou analisar, mas vem antes de tudo do encontro dinâmico com a realidade. Por isso, é 
necessário, para quem faz política pública, ter uma postura de abertura para conhecer o que se revela a cada momento.

Isso, por sua vez, define uma ordem no poder; ou seja, um poder que existe não por um interesse próprio, mas que existe em razão de um bem do povo, de um bem para o homem. "Desse modo, a política deve optar se favorece a sociedade exclusivamente como instrumento, manipulação de um Estado e do seu poder, ou então, se favorece um Estado que seja verdadeiramente leigo, isto é, a serviço da vida social, conforme o conceito de Tomás de Aquino de bem comum" (Giussani, 2001). Conceber e executar uma política pública dessa maneira é uma garantia para o "público" atendido. Só assim a política pública pode realizar o bem do povo. Há hoje uma necessidade premente de tornar esses conceitos, por mais evidente que sejam, operativos o mais possível, dentro da gestão em políticas públicas.

Se deixarmos de lado uma concepção errônea que vê o povo de forma genérica e abstrata, e não como a pessoa que temos diante de nós, verificaremos a necessidade de uma política que esteja preocupada com uma posição ideal. É necessário que o homem público, ou aquele que faz política pública dentro do Estado, esteja preocupado, tenha, antes de tudo, uma posição ideal.

Um partido não pode ser partido de um povo se não tiver um ideal que aglutine aquele povo. Um povo é formado por um acontecimento especial ocorrido no tempo, é unido por um ideal que ele almeja (mais conhecido, menos conhecido, mais intuído, menos intuído). Caso contrário, não se tem um povo, mas um rebanho. É esta a maior tentação de quem detém o poder: transformar o povo em rebanho; preservando todas as formas, mas transformando-o em rebanho! Píer Paolo Pasolini usava a palavra homologação. Uma política que não está preocupada com uma posição ideal, mas em "vencer" por intermédio do poder conquistado, é uma política perversa [...] Uma política, portanto, que esteja preocupada com uma posição ideal estabelece uma ordem educativa e abre espaço a um respiro de liberdade maior e, portanto, a uma criatividade. (Giussani, 2001)

Esses conceitos contêm três afirmações importantes para quem faz gestão pública: uma ordem educativa, um respiro maior de liberdade, uma criatividade. Quem faz política em saúde precisa dessa dimensão educativa; caso contrário, não consegue alcançar os resultados que espera. Podemos citar, por exemplo, a importância fundamental que adquirem os projetos em educação em saúde para promoção e manutenção da saúde da população, ou a educação permanente dos profissionais, diz o Dr. Marco Antônio. É ainda mais importante se compreendemos a educação no seu sentido amplo, como introdução à realidade toda, e não mera transmissão de informações de forma passiva ou unilateral, o que permite um conhecimento da realidade e um trabalho técnico efetivo.

Além disso, um respiro maior de liberdade também é necessário. É preciso que exista um espaço dentro dos programas da Secretaria para valorizar as experiências interessantes que se encontra na comunidade. Como exemplo, o Dr. Marco Antônio cita que, dentro de um dos programas prioritários em Minas, o 
programa "Viva Vida", que tem como meta a diminuição da mortalidade infantil e materna, foi criado um Comitê de Defesa da Vida que reúne hoje cerca de quarenta instituições públicas e privadas. Esse comitê congregou sujeitos que têm se tornado cada vez mais ativos e colaboradores. Ali estão presentes atores como o Fundo Cristão ou a Pastoral da Criança que são colaboradores fundamentais pela capilaridade que possuem e pela potencialidade de alcançar as crianças dentro de um relacionamento muito próximo com a população. Esses atores, com o conhecimento da realidade que adquiriram, têm ajudado o governo a elaborar ações interessantes para enfrentar o problema da mortalidade infantil. O governo precisa também ter um espaço dentro do seu programa de política pública que valorize as ações que esses atores já realizam, chegando mesmo a financiar seu crescimento e desenvolvimento.

Da mesma maneira, a questão da criatividade, que é uma leitura inteligente da realidade. Não se trata de inventar uma nova solução para os problemas, mas de encontrá-la no relacionamento com as instituições e com a população que é usuária dos serviços, valorizando e aperfeiçoando as tentativas que já são feitas em contexto e com particularidades diversas. Como exemplo, o combate à desnutrição: os fatores de risco mais importantes podem ser diferentes de acordo com a comunidade em questão, e, portanto, a intervenção deve levar em consideração essa diversidade.

Falar do homem dentro da história da saúde publica não é falar de um tema estranho. Lendo a história das reformas sanitárias, encontraremos em 1977 a Organização Mundial da Saúde (OMS) com a meta - "Saúde para todos no ano 2000". Ou então, a declaração de Alma Ata de 1978 que define a Atenção Primária à Saúde como sendo:

os cuidados essenciais baseados em métodos práticos, cientificamente bem fundamentados, socialmente aceitáveis e de acesso universal para todos os indivíduos e suas familias, a um custo que a comunidade e o país possam manter em cada fase do desenvolvimento, dentro do espírito de autoconfiança e autodeterminação.

Da mesma forma, a Lei n.8.080/1990 art. 2o․ diz: "A saúde é um direito fundamental do ser humano, devendo o Estado prover as condições indispensáveis ao seu pleno exercício". Ou ainda, a Carta de Ljubljana, da OMS, 1996, que afirma a importância da dignidade humana, eqüidade, solidariedade e ética profissional; da proteção e promoção da saúde centrada em pessoas, permitindo que influam nos serviços de saúde, responsabilizando-se pela própria saúde; e que introduz a questão da qualidade de saúde ligada à qualidade de vida. $\mathrm{O}$ tema da centralidade do ser humano está presente, portanto, em todas as regulamentações, leis e documentos que existem na área da saúde pública. A questão, portanto, é colocar esses conceitos na prática da gestão pública. É necessário que esse direito fundamental do ser humano seja de fato um objetivo perseguido dentro do planejamento das ações, das intervenções em saúde pública. Essa tem sido, afirma o Dr. Marco Antônio, a preocupação ideal dentro da Secretaria de Saúde. 
A Secretaria de Estado de Saúde de Minas Gerais tem dois projetos estruturadores: "Microrregionalização" e "Saúde em Casa". Dentro do plano diretor, todo o Estado de Minas foi dividido em 75 microrregiões, respeitando os princípios de escala, de escopo, o acesso da população, a rede de serviços e pontos de atenção; de forma que ali seja o foco de todo o investimento e desenvolvimento dos programas de saúde. O segundo programa, "Saúde em Casa", é um programa de fortalecimento da atenção primária, especialmente o Programa de Saúde da Família, com o objetivo de aumentar a cobertura nos municípios e melhoria da qualidade da saúde da família. Além disso, a Secretaria tem três programas prioritários: "Viva Vida" (visa reduzir a mortalidade infantil e materna), "ProHosp" (visa ao fortalecimento da rede hospitalar) e "Farmácia de Minas" (visa ao incremento da oferta de medicamentos de atenção básica).

Esses projetos não são em si novidade; a novidade está no método de atuação, se centrado ou não na pessoa concreta, dentro da sua realidade e contexto, para que se possam atingir os objetivos propostos. Ou seja, que exista um interesse real e, portanto, que esse interesse se traduza numa forma de ação operativa. Por exemplo, há hoje vários instrumentos de planejamento de acordo com as áreas de atuação, mas a Secretaria está procurando desenvolver um instrumento único que contemple, antes de tudo, as necessidades locais e, a partir dessas, as necessidades de uma rede de assistência de uma microrregião, e assim progressivamente até chegar ao planejamento do estado. Que o ponto de partida para a programação sejam as necessidades locais significa partir das necessidades dos usuários moradores de uma área de abrangência de uma equipe de saúde da família em qualquer um dos 853 municípios de Minas Gerais. Assim, a programação estadual, sendo um conjunto de ações voltadas a atender a cada e toda necessidade, enfatiza a atenção na pessoa. De um sistema fragmentado, torna-se um sistema integrado e organizado em torno de um eixo: a pessoa como centro.

A partir do esforço de busca de instrumentos que levassem em consideração a pessoa na sua necessidade, a Secretaria de Saúde de Minas está desenvolvendo uma parceria de cooperação técnica com a região da Lombardia da Itália. Na primeira etapa dessa parceria, realizou-se um "Curso de especialização em gestão microrregional de sistemas e serviços de saúde". O interesse da Secretaria por esse curso foi o de melhorar a gestão nas microrregiões, espaço territorial onde os serviços de maior complexidade tecnológica mantêm uma proximidade com o usuário. Em uma segunda etapa, a parceria prevê a realização de pilotos de melhoria de gestão em duas microrregiões, Teófilo Otoni e Juiz de Fora. O curso se desenvolveu em três módulos: institucional, epidemiológico, gerencial. Participaram os gestores da Secretaria, superintendentes, diretores e coordenadores, do nível central e regional. Foi a oportunidade de colocar "todas as cartas na mesa" e avaliar cada atividade da Secretaria, sua utilidade e dificuldade, além de permitir a discussão e implementação de instrumentos novos de gestão. A parceria com a região da Lombardia prevê ainda seminários comparativos para 
implementação de uma nova cultura de gestão profissional e institucional baseada na mudança:

1. Da lógica da oferta (que é uma lógica perversa dentro da saúde pública: disponho de tantas consultas, então, delimito a população a ser atendida) para o conbecimento das necessidades específicas da população e da demanda de serviços gerada por essas necessidades.

2. De um sistema fragmentado de serviços de saúde (onde o posto de saúde não tem um diálogo com o hospital, que, por sua vez, não dialoga com o laboratório etc.) para um sistema integrado, onde a atenção primária tem um papel de coordenação de todo o sistema. Esse sistema integrado de serviços da saúde se torna então um serviço à pessoa pela continuidade da atenção que possibilita e não simplesmente uma série de hospitais, laboratórios e centros de saúde, de uma determinada uma'área geográfica, que prestam serviços a quem "bate na porta". É importante que a atenção primária seja o ponto de coordenação de todo o sistema, pois é quem garante a proximidade e o acompanhamento do usuário, cobrindo todos os ciclos de vida da pessoa/família, desde o nascimento até a velhice, não permitindo que o paciente seja simplesmente encaminhado para uma internação, por exemplo, mas se responsabilizando pelo acompanhamento dele durante e após a internação. A atenção primária tem também um foco sobre a família, que é compreendida não simplesmente como um núcleo sociológico, mas como um sujeito educativo, um sujeito capaz do cuidado em saúde. Permite ainda um enfoque comunitário, através da valorização de todos os recursos existentes na área de abrangência da Equipe de Saúde da Família. Para enfrentar a desnutrição, por exemplo, a equipe de saúde é muito limitada nas suas possibilidades, mas, se ela se envolve em uma rede de cooperação com os outros atores existentes na área, ela tem possibilidades mais concretas de alcançar o resultado de melhoria do estado nutricional das crianças. Essas reflexões têm norteado a elaboração de manuais e linhas guias na Secretaria e a mudança de uma organização classicamente piramidal para uma organização em rede, tendo no centro a atenção primária à saúde.

3. Da gestão das condições agudas para a gestão das condições crônicas. Hoje, $60 \%$ da carga de problemas de saúde no SUS dizem respeito a condições crônicas. Uma projeção da OMS diz que em 2020 a demanda por doenças crônicas como diabetes e hipertensão será de $80 \%$. A condição crônica implica um cuidado, uma abordagem mais ampla do que o reduzido "realizar a consulta e receitar remédio" que ainda caracteriza a saúde pública no Brasil.

Para alcançar esses objetivos, uma das atividades da Secretaria tem sido a construção de linhas guias, como a de Atenção à Saúde da Criança, na qual se incluíram, além de recomendações para o acolhimento da criança, ações de prevenção e promoção à saúde e abordagem clínica das doenças mais freqüentes; uma planilha de programação local que primeiramente indica os passos para conhecimento do público-alvo; no caso da criança, o número de recém-nascidos, 
crianças de zero a um ano e até cinco anos moradoras da 'área de abrangência -e, dentro desse grupo, quais e quantas têm fatores de risco (recém-nascidos prematuros, com baixo peso ou filhos de mães analfabetas), e, em seguida, o conjunto mínimo de atividades para o cuidado daquela criança. Essa abordagem permite o conhecimento e monitorização continuada desse público e faz crescer o vínculo entre os profissionais e a população. Um outro exemplo está no protocolo Assistência Hospitalar ao Neonato, que prevê um Plano de Cuidados para o recémnascido de risco a ser encaminhado, juntamente com o diagnóstico de alta, para a Unidade de Saúde, incluindo orientações como data da primeira consulta de puericultura, particularidades do acompanhamento pelo pediatra, consultas com especialistas ou medicamentos prescritos; ou seja, uma prescrição a médio e longo prazos que permita ao médico de saúde da família acompanhar com precisão aquele recém-nascido.

O conjunto de planilhas de programação para cada doença ou condição possibilita um planejamento local da Unidade Básica de Saúde realista e não genérico, definindo os pontos de atenção necessários para atender os usuários. Esses procedimentos, por sua vez, permitem a definição de um plano de investimentos específico, a definição da programação da atenção farmacêutica, o monitoramento de todas as ações, a educação permanente em saúde e, conseqüentemente, a melhoria da qualidade em saúde. O fato de a Unidade de Saúde conhecer com maior precisão sua área de abrangência, suas necessidades e problemas, permite uma organização da política pública muito mais eficiente.

Por último, Dr. Marco Antônio retoma as considerações filosóficas do início: "Por que não há grandes criadores hoje? Por que é difícil, por que é mais difícil existirem? Porque falta espaço para o respiro criador. É preciso que a política seja exercida por pessoas que tenham realmente interesse pelo homem" (Giussani, 2001). É preciso que quem faz política pública tenha um interesse verdadeiro, e portanto operativo, pelo homem, que inclua o desenvolvimento de ações concretas em favor do homem.

Nota

1 Os dois textos deste dossiê são uma síntese de exposições apresentadas num debate, realizado nos dias $1^{\text {o }}$ e 3 de agosto de 2005, no Instituto de Estudos Avançados da USP, intitulado "Oficina - Diagnóstico e soluções dos problemas alimentares e nutricionais no Brasil, formando parcerias". Os demais trabalhos apresentados nesse seminário serão publicados numa próxima edição desta revista. O presente texto foi baseado nas conferências do professor Enrico Novara, diretor executivo no Brasil da Associação Voluntária para o Serviço Internacional (AVSI), e do professor Marco Antônio Bragança de Matos, responsável pela normalização da atenção à saúde da Secretaria de Estado da Saúde de Minas Gerais. 
Referências bibliográficas

AVSI, CONDER, CITIES ALLIANCE. Plano de Desenvolvimento Social e Ambiental do Programa Ribeira Azul - Projeto de Apoio Técnico e Social na Área do Ribeira Azul (PATS). Salvador: Documento de projeto, 2002.

COGO, L.; CAPITANIO, G. Uma companhia que educa. Belo Horizonte: AVSI, 2004.

GATTI, M. T.; NOVARA, E. The Real City. Methods and actions implemented by AVSI to upgrade informal urban areas. In: MAFFENINI, W. Partnership experience against urban poverty. Milan: Franco Angeli, 2003.

GIUSSANI, L. O eu, o poder e as obras. São Paulo: Cidade Nova, 2001.

JOÃO PAULO II (papa). Redemptoris Missio, n.58-59, 7 de dez., 1990.

NOVARA, E. et al. Pobreza e patrimônio - A comunidade do Planalto II. Belo Horizonte: AVSI, 2003.

NOVARA E. Promover os talentos para reduzir a pobreza. Estudos Avançados, São Paulo, n.48, 2003.

SOLYMOS, G. M. B. Coleção vencendo a desnutrição: abordagem psicológica. São Paulo: Salus Paulista, 2002. (download no site:www.desnutricao.org.br)

REsumo - O ÊXito das políticas públicas depende de diversos fatores. Entre esses, é fundamental o conhecimento da realidade para a definição do conteúdo e da gestão dos programas de utilidade pública. Fundamentar o conhecimento na realidade concreta, ou seja, nas circunstâncias que as pessoas vivem cotidianamente, centrando a atenção na "pessoa" e suas experiências de vida, permite maior eficiência de atuação e nova forma de intervenção, capaz de valorizar os aspectos positivos e as tentativas de resposta às necessidades já construídas pela pessoa e sua comunidade. Fortalecer essas tentativas pode então representar uma decisão importante e inovadora no panorama dos programas públicos.

Palavras-Chave: Políticas públicas, Pessoa, Saúde, Educação, Desenvolvimento urbano.

ABSTRACT - THE SUCCESS of public policies depends on several factors, including the overriding need to understand reality in order to define the content and management of programs for the common good. When knowledge is grounded on actual reality, that is, on the circumstances people must face on a daily basis, and attention is focused on the "individual" and his or her life experiences, efficiency is greatly enhanced and a new form of intervention becomes possible - one that values positive aspects and the attempts to fulfill the needs already established by individuals and their community. Therefore, strengthening such attempts may constitute an important and innovative decision in the public programs environment.

KEYWORDS: Public policies, Person, Health, Education, Urban development.

Ana Lydia Sawaya é professora livre-docente do Departamento de Fisiologia da Universidade Federal de São Paulo e presidente do Centro de Recuperação e Educação Nutricional (Cren).@ - anafisi@ecb.epm.br

Recebido em 17.1.2006 e aceito em 27.1.2006. 